\title{
The Cyclical Behavior of Unemployment and Vacancies with Loss of Skills during Unemployment
}

\author{
Victor Ortego-Marti* \\ University of California Riverside
}

February 22, 2015

\begin{abstract}
This paper studies the cyclical fluctuations in unemployment and vacancies in a search and matching model in which workers lose skills during periods of unemployment. Firms' profits fluctuate more because aggregate productivity affects the economy's average human capital. Moreover, wages for workers with lower levels of human capital are closer to the value of non-market time, leading to more rigid wages. Fluctuations in the vacancyunemployment ratio are larger than in the baseline search and matching model and similar to those we observe in the data.
\end{abstract}

*Department of Economics, University of California Riverside. Sproul Hall 3132, Riverside CA 92521. Email: victor.ortego-marti@ucr.edu. Phone: 951-827-1502. I am grateful to the Associate Editor, two anonymous referees, Marcelle Chauvet, Yu-Chin Chen, Russell Cooper, Joel David, Jang-Ting Guo, Urmee Khan, David Lagakos, David Malueg, Vincenzo Quadrini, Xavier Raurich, Richard Suen, Stephen Turnovsky, Gianluca Violante, Carl Walsh, Joel Watson, Randall Wright and Alwyn Young for invaluable comments and suggestions. I also benefited from helpful discussions with seminar participants at UC Riverside and the 15th Annual Meeting of the Association for Public Economic Theory at the University of Washington. 


\section{Introduction}

Unemployment has dramatic implications for workers' earnings and reemployment prospects. Unemployed workers often suffer important and permanent human capital losses, and workers with long unemployment spells become increasingly detached from the labor market. These negative impacts of unemployment on workers are absent from the baseline version of the Diamond-Mortensen-Pissarides model of equilibrium unemployment (henceforth DMP). At the same time, this workhorse model cannot generate fluctuations in unemployment and vacancies in line with those we observe in the data. Because these fluctuations are driven by firms' hiring decisions, the effect of unemployment on workers' human capital has important implications for the volatility of these fluctuations. Intuitively, firms are likely to hire fewer workers when the pool of unemployed workers worsens in recessions, and to hire more workers when the pool improves in booms. This leads to more volatile unemployment and vacancies. This paper examines whether introducing the loss of human capital during unemployment into an otherwise standard search model generates more sizable fluctuations in unemployment and vacancies.

The influential findings in Shimer (2005) show that, compared to empirical observations, the DMP model is unable to generate large enough fluctuations in its key variable, the ratio of vacancies to unemployment. ${ }^{1}$ As Shimer (2005) shows, the problem in the DMP framework is that wages respond too much to changes in productivity. ${ }^{2}$ When labor productivity increases in a boom the wage responds almost one to one, so firms' profits barely change. This dampens firms' incentives to hire more workers, resulting in a modest increase in the number of posted vacancies. With vacancies unchanged, workers find jobs at the same rate and unemployment remains roughly constant. The same mechanism explains the mild response of vacancies and unemployment to lower labor productivity in recessions.

I present a search and matching model in which workers gradually lose human capital during unemployment. In this framework, labor market fluctuations increase because firms' profits are more volatile. This happens for two reasons. First, aggregate productivity affects the average human capital of the pool of unemployed workers and how profitable a new hire is. When workers lose skills during unemployment, labor productivity is determined by aggregate

\footnotetext{
${ }^{1}$ See also Costain \& Reiter (2008) and Hall (2005) for work with similar findings.

${ }^{2}$ Or to be more precise, profits barely respond to changes in productivity, as Hagedorn \& Manovskii (2008) show.
} 
productivity and the economy's average human capital. Since workers that have experienced more and longer unemployment spells have lower human capital levels, workers' human capital depends on their unemployment history - the cumulative duration of their unemployment spells. Because the economy's human capital improves when workers find jobs more quickly, and worsens when they take longer to find jobs, hiring becomes more profitable in booms and less so in recessions compared to a model without human capital fluctuations. This leads firms to post more vacancies in booms and fewer vacancies in recessions.

The second mechanism operates through wages. As workers accumulate more unemployment history, their productivity and wages decrease. Therefore, the wages of workers with longer unemployment history are closer to the value of non-market time- which includes unemployment benefits, home production and leisure. This makes wages more rigid for this group of workers, in the sense that their wages respond proportionally less to changes in aggregate productivity. As a result profits are more sensitive to changes in aggregate productivity, leading to larger swings in the vacancy-unemployment rate ratio. Hagedorn \& Manovskii (2008) show that higher values of non-market time lead to more rigid wages and more volatile profits. One can view workers with high unemployment history as workers similar to workers in Hagedorn \& Manovskii (2008), although the measure of such workers à la Hagedorn and Manovskii is endogenously determined by labor market flows and the human capital decay process.

I study to what extent the model with loss of skills during unemployment is able to generate sizable fluctuations in the vacancy-unemployment ratio. I derive an expression for these fluctuations that depends only on a set of parameters standard in the literature. The model generates more fluctuations than the baseline DMP model. The improvement is modest for low values of non-market time, but large for the mid-range values used in the literature. For this range of values the model generates fluctuations that closely match those observed in the data.

\section{Related literature.}

This paper is motivated by the findings in Shimer (2005), Hall (2005) and Costain \& Reiter (2008). ${ }^{3}$ A number of papers address these findings. Hall \& Milgrom (2008) consider alternating wage offers instead of the typical Nash bargaining assumption, which leads to some form of wage rigidity. Hagedorn \& Manovskii (2008) use an alternative calibration to Shimer (2005) that leads

\footnotetext{
${ }^{3}$ See also Mortensen \& Nagypal (2007) and (2007b) for further discussion of the Shimer critique. This puzzle is also present using European data, see for example Cardullo \& Guerrazzi (2013).
} 
to larger fluctuations in firms' profits. Pissarides (2009) adds a fixed component to vacancy costs, which makes the expected cost of posting a vacancy less volatile. ${ }^{4}$ A number of papers generate larger fluctuations through some endogenous wage rigidity. With wage rigidity, hiring profits become more volatile, leading to larger labor market fluctuations. ${ }^{5}$ However, none of these papers look at the role of human capital depreciation during unemployment as a source of labor market fluctuations. The advantage of the approach in this paper is that the magnitude of the amplification in fluctuations depends on the rate at which workers lose skills during unemployment, which is directly observable from empirical micro evidence.

Pries (2008), Bils et al. (2012) and Chassamboulli (2013) study how worker heterogeneity affects labor market fluctuations. ${ }^{6}$ In these models, workers have different and permanent differences in productivity. ${ }^{7}$ Empirically this heterogeneity corresponds to a worker fixed effect. One can view this paper as complementary to theirs, given that there is empirical evidence of human capital depreciation due to unemployment even after controlling for fixed-effects and other observables that capture worker ability. A more realistic model would include both types of heterogeneity, the permanent exogenous heterogeneity in their models and the endogenous heterogeneity due to human capital decay. The advantage with this paper is that the endogenous heterogeneity is determined by the rate of human capital depreciation, for which good micro estimates exist, whereas these models must calibrate the exogenous distribution of workers' abilities, which we can not observe in the data.

This paper is also related to a literature that combines search frictions with human capital depreciation during unemployment. In Pissarides (1992) unemployment becomes more persistent when unemployed workers lose skills during unemployment. Ljungqvist \& Sargent (1998) offer an explanation for the high levels of unemployment in Europe compared to the US. ${ }^{8}$ Coles

\footnotetext{
${ }^{4}$ See also the related work in Silva \& Toledo (2009) and (2013).

${ }^{5}$ Menzio (2005) and Kennan (2010) achieve wage rigidity by adding some asymmetric information about match's productivity. Eyigungor (2010) combines specific capital and embodied technology. Rudanko (2011) studies the type of contracts offered by firms when workers are risk averse and unable to fully smooth consumption. In Gertler \& Trigari (2009) wage rigidity is the result of staggered wages. Beauchemin \& Tasci (2013) rely on shocks to job separations and matching efficiency instead of some form of endogenous wage rigidity, but find that this leads to counterfactual cyclicality of job separations.

${ }^{6}$ See also Bils et al. (2011) for a study of labor market fluctuations with wealth heterogeneity and how this affects workers' reservation wage.

${ }^{7}$ In Pries (2008) and Bils et al. (2012) workers also have different job finding and separation rates, whereas in Chassamboulli (2013) some workers with low ability search for jobs but are too unproductive to be hired by firms.

${ }^{8}$ See also the related papers by den Haan, Haefke \& Ramey (2005), and Ljungqvist \& Sargent (2007) and
} 
\& Masters (2000) show that job creation subsidies are a more efficient policy than training for the unemployed. Ortego-Marti (2012) shows that a model similar to that in this paper generates large amounts of frictional wage dispersion. ${ }^{9}$ However, these papers do not investigate the effect on labor market fluctuations.

There is substantial empirical evidence on the effects of unemployment on workers' wages. Fallick (1996) and Kletzer (1998) review some of the findings in the early job displacement literature. ${ }^{10}$ Although the size of the earnings losses depends on the data source and the period or location of the study, this literature finds large and very persistent earning losses among displaced workers. ${ }^{11}$ This paper also draws from empirical evidence in Ortego-Marti (2012) about the effects of unemployment history on workers' wages.

The paper begins by describing the labor market in section 2. Section 2.1 derives the equilibrium wage and shows that it is closer to the value of non-market time for workers with longer histories of unemployment. Section 2.3 derives the distribution of unemployment history among workers. Using the equilibrium conditions in previous sections, section 2.4 provides the equilibrium labor market tightness and its elasticity with respect to labor productivity, which measures labor market fluctuations. Finally, section 3 shows that for a mid-range value of nonmarket time labor market fluctuations are significantly higher in the model with unemployment history and similar to those observed in the data.

\section{Search and Matching Model with Unemployment His- tory}

The labor market is subject to search and matching frictions. ${ }^{12}$ Workers search for jobs and firms for workers. The number of matches formed is given by a matching function $m\left(N^{U}, N^{V}\right)$, (2008).

${ }^{9}$ See also Shimer \& Werning (2006) and Pavoni (2011) for a study of the implications of the loss of skills during unemployment for unemployment insurance, and Fujita (2012) for the the effects on the secular decline in the job separation rate.

${ }^{10}$ See Couch \& Placzek (2010) and von Wachter, Song \& Manchester (2009) for more recent results.

${ }^{11}$ Couch \& Placzek (2010), Jacobson, LaLonde \& Sullivan (1993), Schoeni \& Dardia (2003), von Wachter, Song \& Manchester (2009) use administrative data; Ruhm (1991) and Stevens (1997) use the PSID; and Carrington (1993), Farber (1997), Neal (1995), Topel (1990) use the Displaced Worker Survey (DWS) supplement of the Current Population Survey (CPS).

${ }^{12}$ See Pissarides (2000) for an exposition of the search and matching approach to the labor market. 
where $N^{U}$ is the number of unemployed workers and $N^{V}$ is the number of vacancies. I assume the usual conditions for the matching function, that it is increasing in both its arguments and concave, and that it displays constant returns. With these assumptions, workers find jobs at a rate $f(\theta)=m(1, \theta)$, and firms fill their vacancies at a rate $q(\theta)=m\left(\theta^{-1}, 1\right)$, where labor market tightness $\theta$ is the vacancy-unemployment ratio, so $\theta \equiv N^{V} / N^{U}$. Separations occur at an exogenous rate $s$.

I further assume that workers gradually lose human capital during unemployment at a constant rate $\delta$. Because longer unemployment spells lead to larger human capital losses, a worker's human capital depends on her complete history of unemployment spells. I use the term unemployment history to refer to a worker's cumulative duration of unemployment spells, and denote it by $\gamma$. Given unemployment history $\gamma$, the worker's human capital is given by $h(\gamma)$. This human capital is net of other characteristics. ${ }^{13}$ Normalizing $h(0)=1$, the human capital of a worker with unemployment history $\gamma$ is given by $h(\gamma)=e^{-\delta \gamma}$.

There is some aggregate productivity in the economy that is common to all matches formed, which I denote by $p$. Once the firm and the worker meet, the productivity of the match is given by the product of aggregate productivity $p$ and the worker's human capital $h(\gamma)$. Employed workers receive a wage $w(\gamma, p)$. During unemployment, workers receive income $b$ from nonmarket activities, which includes unemployment benefits, leisure and home production. Firms post vacancies at a flow cost $k$.

Although workers are identical when they join the labor force, they find and lose jobs at random because of search frictions. This generates endogenous distributions $G^{U}(\gamma)$ and $G^{E}(\gamma)$ of unemployment history among unemployed and employed workers. To allow for stationary distributions $G^{U}(\gamma)$ and $G^{E}(\gamma)$, I assume that at a rate $\mu$ workers leave the labor force. Workers who leave the labor force are replaced by new entrants with zero unemployment history. This ensures stationarity of the distributions.

I denote by $U(\gamma)$ and $W(\gamma, p)$ the value functions of unemployment and employment given

\footnotetext{
${ }^{13}$ This paper investigates the fluctuations in unemployment-vacancy ratio generated by the behavior of unemployment history, hence the focus is on human capital net of other observables such as education, occupation, etc. How these other aspects of human capital affect labor market fluctuations is out of the scope of this paper.
} 
unemployment history $\gamma$. They satisfy the following Bellman equations

$$
\begin{aligned}
& (r+\mu) U(\gamma)=b+f(\theta)(\max \{W(\gamma, p), U(\gamma)\}-U(\gamma))+\frac{d U(\gamma)}{d \gamma} \\
& (r+\mu) W(\gamma, p)=w(\gamma, p)-s(W(\gamma, p)-U(\gamma))
\end{aligned}
$$

where $r$ is the interest rate. Intuitively, (1) satisfies that the return to the asset value $U(\gamma)$ using the effective discount rate $r+\mu$-the left-hand side-, must equal the flow payments and changes in the capital value of $U(\gamma)$. The right-hand side of (1) captures that unemployed workers receive payment flows $b$, they find a job at a rate $f(\theta)$, which carries a net gain of $W(\gamma, p)-U(\gamma)$ if the match is productive enough, and that $U(\gamma)$ depreciates while the worker remains unemployed. Similarly, the right-hand side of (2) captures that employed workers receive wages $w(\gamma, p)$ and lose their job at a rate $s$, which carries a net loss of $W(\gamma, p)-U(\gamma)$.

Let $J(\gamma, p)$ denote the value function of a filled position. It satisfies the following Bellman equation

$$
(r+\mu) J(\gamma, p)=h(\gamma) p-w(\gamma, p)-s J(\gamma, p)
$$

Equation (3) captures that when the firm employs a worker with unemployment history $\gamma$, the match produces $h(\gamma) p$, the firm must pay wages $w(\gamma, p)$, and the job is destroyed at a rate $s$, which carries a net loss $J(\gamma, p)$. Using $V$ to denote the value function of a posted vacancy, the following Bellman equation holds

$$
r V=-k+q(\theta) \int_{0}^{\infty} \max \{J(\gamma, p), 0\} d G^{U}(\gamma)
$$

Firms must pay a vacancy cost $k$ while the vacancy remains posted and at a rate $q(\theta)$ the firm draws a job candidate from the pool of unemployed workers, with workers' unemployment history distributed according to $G^{U}(\gamma)$.

I assume free entry in the market for vacancies, so firms post vacancies until the value of a vacancy is zero, i.e. $V=0$. Because of search frictions, there are some rents from forming a match that must be split between the worker and the firm. The surplus $S(\gamma, p)$ of a match 
captures these rents and is given by

$$
S(\gamma, p)=J(\gamma, p)+W(\gamma, p)-U(\gamma)
$$

I assume that the surplus is split according to Nash Bargaining. Therefore, wages satisfy that workers get a share $\beta$ of the surplus and firms a share $1-\beta$, where $\beta$ is workers' bargaining power. Nash Bargaining implies

$$
\beta J(\gamma, p)=(1-\beta)(W(\gamma, p)-U(\gamma))
$$

and in particular $W(\gamma, p)-U(\gamma)=\beta S(\gamma, p)$ and $J(\gamma, p)=(1-\beta) S(\gamma, p)$.

In the model, the surplus from a match becomes zero if workers accumulate too much unemployment history. At that point, the worker collects all the output as a wage and is indifferent between market and non-market activities. This is formally captured by the following result:

Proposition 1. There exists a unique $\bar{\gamma}$ such that

$$
\begin{aligned}
& (r+\mu) U(\bar{\gamma})=b, \quad \text { and } \\
& h(\bar{\gamma}) p=w(\bar{\gamma}, p)
\end{aligned}
$$

The proof is included in the appendix, but I provide some intuition here. Under the Nash Bargaining assumption, the firm must compensate the worker for her outside option, in this case $U(\gamma)$. This outside option includes the constant value of non-market time $b$. Because the value of output declines with unemployment history, output will be unable to cover for payments $b$ to the worker if unemployment history is too large. When unemployment history reaches a certain level $\bar{\gamma}$, the value of the surplus is zero, and from (3) workers collect all the output in the form of wages, i.e. $w(\bar{\gamma}, p)=h(\bar{\gamma}) p$. It follows from this result that $J(\bar{\gamma}, p)=S(\bar{\gamma}, p)=0$.

I assume that when workers accumulate unemployment history beyond $\bar{\gamma}$, firms can assign them to a zero surplus position. This is similar to Pavoni \& Violante (2007) and Pavoni et al. (2012), where workers can always be assigned to a low skill job that is not subject to human capital decay. This assumption is equivalent to assuming a lower bound for human capital 
and that workers who reach this lower bound are indifferent between market and non-market activities, which is reasonable and consistent with previous studies.

Given this assumption and proposition 1, (1) simplifies to

$$
\begin{aligned}
& \qquad \begin{array}{l}
(r+\mu) U(\gamma)=b+f(\theta)(W(\gamma, p)-U(\gamma))+\frac{d U(\gamma)}{d \gamma}, \forall \gamma \leq \bar{\gamma} \\
\text { and }(r+\mu) U(\gamma)=b, \forall \gamma>\bar{\gamma}
\end{array}
\end{aligned}
$$

Further, the Bellman equation for posted vacancies simplifies to

$$
r V=-k+q(\theta) \int_{0}^{\bar{\gamma}} J(\gamma, p) d G^{U}(\gamma)
$$

\subsection{Wages}

I begin by expressing wages as a function of productivity and $U(\gamma)$. I then proceed to solve for $U(\gamma)$ to derive the equilibrium wage. Using (2) yields

$$
(r+\mu+s)(W(\gamma, p)-U(\gamma))=w(\gamma, p)-(r+\mu) U(\gamma)
$$

Combing the above expression with (3) and Nash Bargaining gives wages as a function of $U(\gamma)$

$$
w(\gamma, p)=\beta h(\gamma) p+(1-\beta)(r+\mu) U(\gamma)
$$

Consider now equation (9). Solving for $U(\gamma)$ in (9) as a differential equation in $\gamma$ gives

$$
U(\gamma)=\int_{\gamma}^{\bar{\gamma}}\left(e^{-\alpha_{1}(\Gamma-\gamma)} b\right) d \Gamma+f(\theta) \int_{\gamma}^{\bar{\gamma}}\left(e^{-\alpha_{1}(\Gamma-\gamma)} \frac{\beta h(\gamma) p}{r+\mu+s}\right) d \Gamma+e^{-\alpha_{1}(\bar{\gamma}-\gamma)} U(\bar{\gamma})
$$

where $\alpha_{1} \equiv r+\mu+\beta f(\theta)(r+\mu) /(r+\mu+s)$. The above expression provides some useful intuition. The value of unemployment captures all the future flows from unemployment, using $\alpha_{1}$ as the discount factor. While unemployment history is lower than $\bar{\gamma}$ workers receive at least flow payments $b$-first term on the right-hand side of (14). In addition to this flow, at a rate $f(\theta)$ workers find a job and get a share $\beta$ of future output - second term on the right-hand side. Finally, when workers accumulate unemployment history $\bar{\gamma}$, the value of unemployment 
is simply $U(\bar{\gamma})=b /(r+\mu)$.

Combing the result in proposition 1 with the wage in (13) gives the following condition for human capital at the terminal level of unemployment history $\bar{\gamma}$

$$
h(\bar{\gamma}) p=b .
$$

Solving equation (14) and using (15), $(r+\mu) U(\gamma)$ simplifies to

$$
\begin{aligned}
(r+\mu) U(\gamma)= & \left(\frac{\left(r+\mu+s+\delta \frac{r+\mu+s}{r+\mu}\right) e^{-\alpha_{1}(\bar{\gamma}-\gamma)}}{r+\mu+s+\beta f(\theta)+\delta \frac{r+\mu+s}{r+\mu}}+\frac{(r+\mu+s)\left(1-e^{-\alpha_{1}(\bar{\gamma}-\gamma)}\right)}{r+\mu+s+\beta f(\theta)}\right) b \\
& +\left(\frac{\beta f(\theta)}{r+\mu+s+\beta f(\theta)+\delta \frac{r+\mu+s}{r+\mu}}\right) h(\gamma) p .
\end{aligned}
$$

Finally, substituting (16) into (13) gives the final expression for wages

$$
\begin{aligned}
w(\gamma, p)=(1-\beta) & \left(\frac{\left(r+\mu+s+\delta \frac{r+\mu+s}{r+\mu}\right) e^{-\alpha_{1}(\bar{\gamma}-\gamma)}}{r+\mu+s+\beta f(\theta)+\delta \frac{r+\mu+s}{r+\mu}}+\frac{(r+\mu+s)\left(1-e^{-\alpha_{1}(\bar{\gamma}-\gamma)}\right)}{r+\mu+s+\beta f(\theta)}\right) b \\
& +\beta\left(\frac{r+\mu+s+f(\theta)+\delta \frac{r+\mu+s}{r+\mu}}{r+\mu+s+\beta f(\theta)+\delta \frac{r+\mu+s}{r+\mu}}\right) h(\gamma) p
\end{aligned}
$$

Note that when $\delta$ equals $0, \bar{\gamma}$ tends to infinity because (15) implies $\bar{\gamma}=-\log (b / p) / \delta$. So the wage expression in (17) collapses to that in the standard DMP model. ${ }^{14}$

\subsection{Endogenous wage rigidity}

I now derive an expression for wages $w(\gamma, p)$ that provides some helpful intuition for why wages are endogenously more rigid with human capital decay. It further allows for a useful comparison with the baseline DMP model. Solving $U(\gamma)$ as a differential equation, and using

\footnotetext{
${ }^{14}$ That is, with $\delta=0$ the wage collapses to

$$
w=\frac{(1-\beta)(r+\mu+s) b+\beta(r+\mu+s+f(\theta)) p}{r+\mu+s+\beta f(\theta)} .
$$
}


that $(r+\mu) U(\bar{\gamma})=b$, gives

$$
(r+\mu) U(\gamma)=b+f(\theta) \int_{\gamma}^{\bar{\gamma}}(r+\mu) e^{-(r+\mu)(\Gamma-\gamma)} \beta S(\Gamma, p) d \Gamma
$$

Compared to the standard DMP model, in (18) workers must now integrate the match surplus over future values of unemployment history to account for human capital depreciation. This is the only difference in the value of unemployment between the two models. ${ }^{15}$ The integral in (18) captures the option value of searching - the fact that unemployed workers find jobs at a rate $f(\theta)$, taking into account future depreciation in human capital if the worker takes longer to find a job.

Applying Nash bargaining to (3) and (12), and substituting for $U(\gamma)$ using (18), gives the following expression for wages

$$
w(\gamma, p)=\beta h(\gamma) p+(1-\beta) b+(1-\beta) f(\theta) \int_{\gamma}^{\bar{\gamma}}(r+\mu) e^{-(r+\mu)(\Gamma-\gamma)} \beta S(\Gamma, p) d \Gamma
$$

As with the value of unemployment, the only difference with the standard DMP model is that wages take into account the depreciation process during unemployment. ${ }^{16}$ However, with human capital decay both the surplus $S(\gamma, p)$ and match productivity $h(\gamma) p$ decrease with unemployment history, so wages are closer to the value of non-market time $b$ for workers with longer histories of unemployment. This leads to more rigid wages, in the sense that their elasticity with respect to labor productivity is smaller. As a result, the labor market becomes more volatile.

That higher values of non-market activities $b$ lead to more rigid wages and larger fluctuations in labor market tightness is a known result in the literature, and is discussed among others by Mortensen \& Nagypal (2007), Hagedorn \& Manovskii (2008) and Hall \& Milgrom (2008). However, in this paper some wages are closer to the value of non-market activities endogenously, not by assuming larger values for $b$. In Hagedorn \& Manovskii (2008), the value of non-

\footnotetext{
${ }^{15}$ More specifically, in the standard DMP model the value of unemployment $U$ is given by $(r+\mu) U=$ $b+f(\theta) \beta S(p)$. When $\delta=0, \bar{\gamma}=\infty$ and $S(\gamma, p)$ does not depend on $\gamma$, i.e. $S(\gamma, p)=S(p)$. So when $\delta$ equals 0 , (18) yields the Bellman equation for the DMP model, i.e. $(r+\mu) U=b+f(\theta) \beta S(p)$.

${ }^{16}$ In the standard model one can use that surplus $S(p)$ satisfies $(1-\beta) S(p)=k / q(\theta)$, thus giving the textbook expression $w(p)=\beta p+(1-\beta) b+\beta \theta k$. The last term, $\beta \theta k$, captures the option value of search, and equals the integral term in (19) when $\delta=0$.
} 
market time is close to productivity, and the authors show that this delivers large labor market fluctuations. One way to interpret the mechanism in this paper is that because of human capital depreciation some workers are similar to workers in Hagedorn \& Manovskii (2008), for whom their marginal product of labor is close to the value of non-market activities. The measure of such workers à la Hagedorn and Manovski arises endogenously and depends on the value of nonmarket activities $b$ and the rate $\delta$ at which skills depreciate. The larger these two parameters are, the larger the measure of workers à la Hagedorn and Manovski. ${ }^{17}$

\subsection{Unemployment History Distribution}

When deciding how many vacancies to post, firms look at the expected profits from a match. Since the productivity of a match depends on aggregate productivity $p$ and human capital $h(\gamma)$, computing expected profits requires knowledge of the endogenous distributions $G^{U}(\gamma)$ and $G^{E}(\gamma)$. To derive these distributions, I look at flows among different groups of workers. Consider the group of workers with unemployment history lower than a given $\gamma$. In steady-state the flows in and out of this group of workers must be equal. In particular, stationarity requires that the following flow equation must hold

$$
g^{U}(\gamma) N^{U}+(f(\theta)+\mu) G^{U}(\gamma) N^{U}=s G^{E}(\gamma) N^{E}+\mu\left(N^{E}+N^{U}\right)
$$

where $N^{U}$ and $N^{E}$ are the number of unemployed and employed workers, and $g^{U}(\gamma)=d G^{U}(\gamma) / d \gamma$ is the probability density function. The left-hand side of (20) represents the flows out of the group of workers with unemployment history lower than $\gamma$. The first term accounts for workers who have unemployment history exactly equal to $\gamma$ and the second term for workers who either find a job or leave the labor force at a rate $\mu$. The right-hand side captures the flows into the group of workers with unemployment history lower than $\gamma$, which consist of workers who lose

\footnotetext{
${ }^{17}$ Hagedorn \& Manovskii (2008) already suggest in their conclusion the potential for human capital decay to justify that marginal productivity is close to the value of non-market activity, but the authors do not explore this possibility. To quote Hagedorn \& Manovskii (2008), "[i]n addition, our finding [that the value of nonmarket activity is fairly close to market productivity] does not rule out that becoming unemployed can cause noticeable distress for some displaced workers, as found in Louis S. Jacobsen, Robert J. LaLonde, and Daniel G. Sullivan (1993). This distress is caused not by the search frictions of the MP model but, more likely, by the loss of the worker's union status or the loss in the value of the worker's occupation-specific human capital (see Gueorgui Kambourov and Manovskii 2008). In other words, in a world with worker heterogeneity, there may be individuals with $p$ much higher than $z$, whose $p$ declines substantially upon displacement. Given that our model does not consider heterogeneity in $p$ values, it does not speak to this issue."
} 
their job and new entrants to the labor market.

If we now consider the pool of unemployed workers, again flows out and into this group must be equal to guarantee stationarity. This gives the following flow equation

$$
(f(\theta)+\mu) N^{U}=s N^{E}+\mu\left(N^{E}+N^{U}\right)
$$

where the left-hand side captures the flows out and the right-hand side the flows into the pool of unemployed. The above equation gives an expression for the ratio $N^{E} / N^{U}$

$$
\frac{N^{E}}{N^{U}}=\frac{f(\theta)}{s+\mu}
$$

In particular, (22) implies that the unemployment rate $u$ is given by

$$
u=\frac{s+\mu}{s+\mu+f(\theta)}
$$

Finally, consider the group of employed workers with unemployment history lower than a given $\gamma$. The following flow equation holds

$$
f(\theta) G^{U}(\gamma)=(s+\mu) G^{E}(\gamma) \frac{N^{E}}{N^{U}}
$$

Substituting (22) into the above flow equation gives that $G^{U}(\gamma)=G^{E}(\gamma)$. Combining this result with (22) and (20) gives the following differential equation in $G^{U}(\gamma)$

$$
g^{U}(\gamma)+\frac{\mu(f(\theta)+s+\mu)}{s+\mu} G^{U}(\gamma)=\frac{\mu(f(\theta)+s+\mu)}{s+\mu}
$$

Solving the differential equation yields

$$
G^{U}(\gamma)=1-e^{-\alpha_{3} \gamma}
$$

where $\alpha_{3} \equiv \mu(f(\theta)+s+\mu) /(s+\mu)$, i.e. the distribution is exponential with parameter $\alpha_{3}$. 


\subsection{Measuring fluctuations in labor market tightness}

I follow the standard approach in the literature and measure fluctuations in the labor market tightness with comparative statics results by looking at the response of the equilibrium labor market tightness to changes in labor productivity. Shimer (2005) and Mortensen \& Nagypal (2007) show that for the standard DMP model the comparative statics results are a good approximation of the response of the full dynamic model. ${ }^{18}$ Intuitively, with very persistent productivity and a high job finding rate, unemployment adjusts very quickly to its steady-state value. This result is more formally discussed in Mortensen \& Nagypal (2007).

In the model, labor market tightness $\theta$ and the unemployment history threshold $\bar{\gamma}$ are endogenous jump variables that adjust immediately to their steady-state values. The only element in the model that may have a slow adjustment is the distribution of unemployment history $G^{U}(\gamma) \cdot{ }^{19}$ Because labor productivity depends on this distribution, comparative statics may be a weak approximation of the dynamic model if the adjustment is slow.

To provide some evidence on the distribution's adjustment pace, I simulate the response of $G^{U}(\gamma)$ to a change in the job finding rate - the only endogenous variable that affects $G^{U}(\gamma)$. I begin by generating an artificial panel of 100,000 workers with unemployment histories that approximate the initial steady state distribution. Given this initial distribution, I consider a $1 \%$ permanent deviation in the job finding rate, and simulate the evolution of the distribution $G^{U}(\gamma)$ given the new labor market flows. I run the same exercise for 1000 artificial panels and compare the simulated distributions to the new steady state distribution. The appendix contains more details on the algorithm and simulation.

The distribution of unemployment history converges very quickly to its stationary distribution, suggesting that comparative statics results are a good approximation of the full dynamic model. After 7 months from the initial shock, the average unemployment history for the simulated panels is 36.22 months. Compared to an average 36.20 months in steady state, the average from the simulations is within $0.05 \%$ of the new steady state value. ${ }^{20}$ Because the distribution

\footnotetext{
${ }^{18}$ See also Mortensen \& Nagypal (2007b), Pissarides (2009) and Silva \& Toledo (2013) for other work that uses the same approach.

${ }^{19} \mathrm{~A}$ similar issue arises in the random matching model with endogenous separations, as discussed in Mortensen \& Nagypal (2007b). There, the distribution of workers across productivity levels determines labor productivity. When aggregate productivity changes, so does this distribution. Whether or not this adjustment is slow is not addressed in their paper.

${ }^{20}$ As a comparison, the unemployment rate from the simulations is $7.48 \%$ compared to a steady state value of
} 
of unemployment history is exponential, this statistics measures both the average and dispersion in the distribution. These results suggest that the convergence is very fast. Intuitively, the job finding rate is so large compared to the other parameters that determine the distribution $G^{U}(\gamma)$, that the response of $f(\theta)$ dominates the other flows. As a result, $G^{U}(\gamma)$ converges very quickly to its stationary distribution.

\subsection{Equilibrium labor market tightness}

Equilibrium labor market tightness $\theta$ is determined by the usual job creation condition. Combining (11) with the free entry condition for vacancies $V=0$, and substituting (3) yields

$$
\frac{k}{q(\theta)}=\int_{0}^{\bar{\gamma}} \frac{h(\gamma) p-w(\gamma, p)}{r+\mu+s} d G^{U}(\gamma)
$$

It will be convenient to denote the expected profit from filling a vacancy by the function $\Phi(\theta, \bar{\gamma}, p)$, i.e. define $\Phi(\theta, \bar{\gamma}, p)$ as

$$
\Phi(\theta, \bar{\gamma}, p) \equiv \int_{0}^{\bar{\gamma}}(h(\gamma) p-w(\gamma, p)) d G^{U}(\gamma)
$$

The expected profit from filling a vacancy $\Phi(\theta, \bar{\gamma}, p)$ depends on $f(\theta)$ and $p$ through the usual mechanism in the standard search and matching model. Higher $f(\theta)$ improves workers outside option, thus raising their wage, and higher $p$ increases both match productivity and wages. However, the expected value $\Phi(\theta, \bar{\gamma}, p)$ further depends on $f(\theta)$ and $\bar{\gamma}$ through the effect on the average human capital level.

The derivation of $\Phi(\theta, \bar{\gamma}, p)$ requires taking many integrals and yields a somewhat cumbersome expression. Substituting the distribution $G^{U}(\gamma)$ from $(26)$ into $(28)$ and solving for the

7.54\%. Looking at average human capital, which is what matters for job creation and the equilibrium tightness, instead of unemployment history gives a similar picture. 
integrals eventually gives

$$
\begin{aligned}
& \Phi(\theta, \bar{\gamma}, p)=\left\{\left(1-e^{-\left(\delta+\alpha_{3}\right) \bar{\gamma}}\right) \cdot \frac{\alpha_{3}}{\alpha_{3}+\delta} \cdot \frac{(1-\beta)\left(r+\mu+s+\delta \frac{r+\mu+s}{r+\mu}\right)}{r+\mu+s+\beta f(\theta)+\delta \frac{r+\mu+s}{r+\mu}}\right\} p \\
& +\left\{\beta\left(\frac{r+\mu+s+f(\theta)+\delta \frac{r+\mu+s}{r+\mu}}{r+\mu+s+\beta f(\theta)+\delta \frac{r+\mu+s}{r+\mu}}-\frac{r+\mu+s+f(\theta)}{r+\mu+s+\beta f(\theta)}\right) \cdot \frac{\alpha_{3}}{\alpha_{1}-\alpha_{3}} \cdot\left(e^{-\alpha_{3} \bar{\gamma}}-e^{-\alpha_{1} \bar{\gamma}}\right)\right\} b \\
& -\left\{(1-\beta)\left(1-e^{-\alpha_{3} \bar{\gamma}}\right) \cdot \frac{r+\mu+s}{r+\mu+s+\beta f(\theta)}\right\} b .
\end{aligned}
$$

The appendix includes some further details on how to derive (29). A nice feature of (29) is that it depends only on known parameters that are standard in the literature.

\subsection{Response to aggregate productivity}

In the standard DMP model with exogenous separations, there is no distinction between aggregate productivity and labor productivity. However, in the model with unemployment history labor productivity is endogenous, so the response to aggregate productivity and labor productivity are different. ${ }^{21}$ As a result, the appropriate measure of labor market fluctuations is the response to labor productivity.

Deriving the response of market tightness to aggregate productivity requires taking a number of integrals, which makes the solution somewhat cumbersome, but it is otherwise straightforward. Most importantly, one can find a closed form solution that depends only on a set of known parameters.

Taking logs and differentiating (27) with respect to $p$ yields

$$
-\frac{q^{\prime}(\theta)}{q(\theta)} \frac{d \theta}{d p}=\frac{\Phi_{\theta}(\theta, \bar{\gamma}, p) \frac{d \theta}{d p}+\Phi_{\bar{\gamma}}(\theta, \bar{\gamma}, p) \frac{d \bar{\gamma}}{d p}+\Phi_{p}(\theta, \bar{\gamma}, p)}{\Phi(\theta, \bar{\gamma}, p)}
$$

where the subscripts denote partial derivates, i.e. $\Phi_{x}(\theta, \bar{\gamma}, p) \equiv \partial \Phi(\theta, \bar{\gamma}, p) / \partial x$. The above equation provides some useful intuition. In response to changes in aggregate productivity $p$, the profitability of a job $\Phi(\theta, \bar{\gamma}, p)$ changes through three channels. First, higher aggregate

\footnotetext{
${ }^{21}$ This is similar to Mortensen \& Nagypal (2007b), in the Mortensen \& Pissarides (1994) model with endogenous separations labor productivity is endogenous. I thank two anonymous referees for helpful comments and suggestions on this issue.
} 
productivity $p$ leads to higher job finding rates, which improves workers' average human capital. It also increases the value of unemployment and drives wages up, as in the baseline model. This is captured by the first term on the right-hand side of (30). Second, with higher aggregate productivity some matches yield some positive surplus now, which is captured by the change in the unemployment history threshold $\bar{\gamma}$. This corresponds to the second term on the right-hand side of (30). Finally, an increase in $p$ increases the profitability of the job as in the standard DMP model. Note that the profitability of a job changes relatively more for matches with higher levels of unemployment history, because wages for those matches are closer to the value of non-market time $b$, as (19) shows.

Let $\eta$ denote the elasticity of $q(\theta)$ with respect to $\theta$, i.e. $\eta \equiv-q^{\prime}(\theta) \theta / q(\theta)$. Further, let $\varepsilon_{\theta, p}$ denote the elasticity of $\theta$ with respect to $p$, i.e. $\varepsilon_{\theta, p} \equiv(d \theta / d p) \cdot(p / \theta)$. Because $f^{\prime}(\theta) \theta / f(\theta)=1-\eta$ and $\Phi(\theta, \bar{\gamma}, p)$ depends on $\theta$ only through $f(\theta)$, we can express $\Phi_{\theta}(\theta, \bar{\gamma}, p) \cdot \theta$ as

$$
\Phi_{\theta}(\theta, \bar{\gamma}, p) \cdot \theta=\Phi_{f(\theta)}(\theta, \bar{\gamma}, p) \cdot(1-\eta) \cdot f(\theta)
$$

Rearranging (30) and using the above result gives

$$
\varepsilon_{\theta, p}=p \cdot\left(\frac{\Phi_{\bar{\gamma}}(\theta, \bar{\gamma}, p) \frac{d \bar{\gamma}}{d p}+\Phi_{p}(\theta, \bar{\gamma}, p)}{\Phi(\theta, \bar{\gamma}, p)}\right) \cdot\left(\eta-(1-\eta) f(\theta) \frac{\Phi_{f(\theta)}(\theta, \bar{\gamma}, p)}{\Phi(\theta, \bar{\gamma}, p)}\right)^{-1}
$$

A nice feature of (32) is that it is also uniquely determined by a set of standard parameters in the literature. The closed form expressions for the partials $\Phi_{x}(\theta, \bar{\gamma}, p) \equiv \partial \Phi(\theta, \bar{\gamma}, p) / \partial x$ in $(32)$ are included in the appendix.

Let $\bar{y}$ denote the endogenous average labor productivity. Given the assumption that workers are assigned to a zero surplus match when unemployment history hits $\bar{\gamma}$, labor productivity is given by $h(\gamma) p$ when $\gamma \leq \bar{\gamma}$ and by $h(\bar{\gamma}) p=b$ when $\gamma>\bar{\gamma}$. As a result, average labor productivity is given by

$$
\bar{y}=\frac{\alpha_{3}}{\alpha_{3}+\delta}\left(1-e^{-\left(\alpha_{3}+\delta\right) \bar{\gamma}}\right) p+e^{-\alpha_{3} \bar{\gamma}} b
$$

The response of labor productivity to changes in aggregate productivity is thus given by $d \bar{y} / d p=\partial \bar{y} / \partial p+(\partial \bar{y} / \partial f(\theta))(1-\eta) f(\theta) \varepsilon_{\theta, p}+(\partial \bar{y} / \partial \bar{\gamma})(d \bar{\gamma} / d p)$. The appendix contains the closed- 
form expression for $d \bar{y} / d p$.

In response to shocks to aggregate productivity $p$, the overall elasticity of labor market tightness with respect to the endogenous labor productivity $\bar{y}$, which I denote $\varepsilon_{\theta, \bar{y}}$ is then given by the ratio of the two elasticities

$$
\varepsilon_{\theta, \bar{y}}=\varepsilon_{\theta, p} / \varepsilon_{\bar{y}, p},
$$

where $\varepsilon_{\bar{y}, p}=(d \bar{y} / d p) \cdot(p / \bar{y})$.

\section{Quantifying labor market fluctuations}

I now calibrate the model and quantify the amount of labor market fluctuations, as captured by the elasticity $\varepsilon_{\theta, \bar{y}}$ of labor market tightness in (34). Labor market fluctuations are uniquely determined by $\{b, f(\theta), s, \mu, r, \beta, \eta, \delta\}$. For most of these values the calibration is standard in the literature.

\subsection{Calibration}

Table 1 summarizes the calibration values. Rates are measured monthly. Using the estimates in Shimer (2005), the job finding rate $f(\theta)$ is 0.45 and the separation rate $s$ is 0.035 . The rate at which workers leave the labor force $\mu$ is calibrated so that workers stay in the labor force for 40 years on average, which gives a value for $\mu$ of 0.0021 . The interest rate $r$ is consistent with a 5 percent annual interest rate. I use $\eta=0.5$, which is within the range of values for the matching function in Petrongolo \& Pissarides (2001). ${ }^{22}$ Further, I set $\beta=\eta$, which satisfies the Hosios-Pissarides condition. In section 3.2, I discuss in more detail the role of non-market time $b$, and show how different values of $b$ affect the elasticity of market tightness $\varepsilon_{\theta, \bar{y}}$.

Finally, I build on evidence in Ortego-Marti (2012) to calibrate $\delta$, the rate at which workers lose human capital during unemployment. This study uses the Panel Study of Income Dynamics (PSID) from 1968 to 1997 to construct workers' unemployment history $\gamma_{i t}$. To find the effect of unemployment history on wages, Ortego-Marti (2012) regresses log wages on unemployment

\footnotetext{
${ }^{22}$ Shimer (2005) uses a value of 0.72 for $\eta$, but as Mortensen \& Nagypal (2007) argues, this value is on the upper bound of the parameter range and leads to lower labor market fluctuations.
} 
history and other covariates and worker observables, i.e.

$$
\log W_{i t}=\alpha_{i}-\delta \gamma_{i t}+X_{i t} \beta+\epsilon_{i t}
$$

where $X_{i t}$ is a set of covariates commonly used in Mincerian regressions, such as experience, occupation, region and so on. ${ }^{23}$ This empirical strategy finds that one added month of unemployment history is associated with a $1.22 \%$ wage drop. ${ }^{24}$ Ortego-Marti (2012) further shows that these human capital losses are very persistent, which supports the model's assumption of permanent human capital losses. ${ }^{25}$

I use this estimate to calibrate the rate at which workers lose human capital during unemployment $\delta$. The counterpart of this empirical value in the model is the average semi-elasticity of wages with respect to unemployment history $\gamma$, i.e. $E(\partial \log (w) / \partial \gamma)$. Using the expression for wages in (17) and differentiating with respect to unemployment history $\gamma$ gives

$$
\begin{aligned}
\frac{d w}{d \gamma}= & \left\{\frac{\beta(1-\beta) f(\theta) \alpha_{1} e^{-\alpha_{1}(\bar{\gamma}-\gamma)} \delta\left(\frac{r+\mu+s}{r+\mu}\right)}{\left(r+\mu+s+\beta f(\theta)+\delta\left(\frac{r+\mu+s}{r+\mu}\right)\right)(r+\mu+s+\beta f(\theta))}\right\} b \\
& -\left\{\beta \frac{r+\mu+s+f(\theta)+\delta\left(\frac{r+\mu+s}{r+\mu}\right)}{r+\mu+s+\beta f(\theta)+\delta\left(\frac{r+\mu+s}{r+\mu}\right)}\right\} \delta h(\gamma) p .
\end{aligned}
$$

To find the average semi-elasticity in the model, I combine (17) and (36) and use numerical integration to calculate

$$
E\left(\frac{d w / d \gamma}{w}\right)=\int_{0}^{\bar{\gamma}}\left(\frac{d w / d \gamma}{w}\right) d G^{U}(\gamma)
$$

The value for the depreciation rate $\delta$ is calibrated so that the average semi-elasticity in the model equals its empirical counterpart.

\footnotetext{
${ }^{23}$ Ortego-Marti (2012) contains more details on the empirical work and shows that the results are robust to different specifications.

${ }^{24}$ This value is in general smaller than the estimates found in the displaced workers literature, but broadly similar. These studies focus on a set of workers that are very attached to their sector or employer - for example, they usually focus on workers with a minimum tenure on the job. Not surprisingly these workers have accumulated more specific human capital on average, so displacement leads to larger wage losses. Using their values would improve the results, so the chosen calibration for $\delta$ is not controversial.

${ }^{25}$ For example, unemployment history that occurred more than 7 years ago is still associated with a $1.04 \%$ wage loss. These results are also consistent with evidence from the job displacement literature that earnings losses are persistent.
} 


\subsection{Results}

Shimer (2005) reports that in the data labor market tightness is 20 times more volatile than labor market productivity. However, many factors other than labor productivity affect fluctuations in labor market tightness. To address this issue, Mortensen \& Nagypal (2007) regress labor market tightness on labor productivity, which yields a coefficient of 7.56. This regression coefficient corresponds to the elasticity of labor market tightness with respect to aggregate productivity and is thus the empirical counterpart of (32). Intuitively, the search and matching framework with aggregate productivity as its only source of fluctuations should only aim to account for this level of fluctuations. Any fluctuations in $\theta$ that are not correlated with aggregate productivity $p$ cannot be accounted for without including further sources of fluctuations. Therefore, I investigate whether the model with unemployment history is able to generate a value of 7.56 for the elasticity $\varepsilon_{\theta, \bar{y}}$.

In the model with unemployment history the average labor productivity is $\bar{y}$, whereas in the baseline model it is simply $p$, i.e. $\bar{y}=p$. So both models are comparable only if the effective replacement ratio $\tilde{b}=b / \bar{y}$ is the same. Table 2 shows the elasticity of market tightness $\varepsilon_{\theta, \bar{y}}$ for different values of the effective replacement ratio $\tilde{b}$. The calculations use the same replacement ratio in both models. ${ }^{26}$ This elasticity is then compared to that in the baseline DMP model, which corresponds to $\delta=0$ and is given by

$$
\varepsilon^{D M P}=\frac{p}{p-\tilde{b}} \cdot \frac{r+s+\beta f(\theta)}{\eta(r+s)+\beta f(\theta)}
$$

The model generates larger fluctuations in labor market tightness $\theta$ compared to the baseline DMP model. ${ }^{27}$ For low values of non-market time $\tilde{b}$ the improvement is modest. When the value of non-market time equals 0.40, as in Shimer (2005), the elasticity of labor market tightness increases from 1.83 to $1.90 .^{28}$ This is barely a $4 \%$ improvement over the baseline and the

\footnotetext{
${ }^{26}$ More specifically, I use the effective replacement ratio from the model with unemployment history as the value of non-market activities when I calculate the elasticity in the baseline model. This guarantees the same replacement ratio in both models. If instead ones uses the same value for $b$ in both models, the fluctuations in the baseline model reported in table 2 would be lower, but would leave those in the model with unemployment history unchanged.

${ }^{27}$ As a robustness check, the elasticity $\varepsilon_{\theta, \bar{y}}$ using the calibration in Shimer (2005) with $\delta=0$ and $\mu=0$ delivers an elasticity of 1.72, the same value that Mortensen \& Nagypal (2007) find for the baseline DMP model with Shimer's calibration, as one would expect.

${ }^{28}$ Shimer (2005) uses a replacement ratio of 0.40 for his calibration based on unemployment insurance replacement ratios.
} 
elasticity is still far from the empirical target. However, when $\tilde{b}$ is sufficiently high, the model with unemployment history is a significant improvement over the baseline and generates labor market fluctuations similar to those observed in the data. With non-market time equal to 0.73 , as in Hall \& Milgrom (2008), the elasticity of market tightness in the model with unemployment history is $7.88 .^{29}$ In this case the model with unemployment history can account for the observed level of fluctuations in labor market tightness. By contrast, the elasticity in the baseline model is 3.96. Intuitively, for a given skills depreciation rate $\delta, \tilde{b}$ determines the measure of workers à la Hagedorn \& Manovskii (2008). The model generates enough fluctuations if this measure of workers is large enough, which is the case when the replacement ratio is the one in Hall \& Milgrom (2008). ${ }^{30}$

One can also measure the elasticities of unemployment and the job finding rate $\varepsilon_{u, \bar{y}}$ and $\varepsilon_{f, \bar{y}}$ with respect to labor productivity $\bar{y}$. The elasticities are given by $\varepsilon_{f, \bar{y}}=\varepsilon_{f, p} / \varepsilon_{\bar{y}, p}$ and $\varepsilon_{u, \bar{y}}=\varepsilon_{u, p} / \varepsilon_{\bar{y}, p}$. Differentiating the job finding rate and unemployment in (23) gives that $\varepsilon_{f, p}=(1-\eta) \varepsilon_{\theta, p}$ and $\varepsilon_{u, p}=\varepsilon_{u, f} \cdot \varepsilon_{f, p}$, where the elasticity $\varepsilon_{u, f}$ is given by $-f /(f+s+\mu)$. Using the results derived earlier, the elasticity of the job finding rate is 3.94, and the elasticity of unemployment is -3.64. Chassamboulli (2013) reports, using evidence from Shimer (2005), that the empirical counterparts for these elasticities are 2.34 and -3.88 . Therefore, the model is also able to generate sizable fluctuations in both the job finding rate and unemployment.

\subsection{Disentangling the different effects}

This section aims to disentangle the magnitude of each mechanism at the source of labor market fluctuations in the model with skills decay. ${ }^{31}$ In doing so, it will be helpful to compare the different effects to their counterpart in the baseline DMP model. I begin by deriving the

\footnotetext{
${ }^{29}$ The value of non-market time $\tilde{b}$ includes unemployment insurance payments (UI), leisure and home production. Hall \& Milgrom (2008) use evidence from the empirical Frisch elasticities to calibrate the value of non-market time. They find that this value should be between 0.63 and 0.83 , hence they use the mid-point value of 0.73 . The interval comes from the fact that empirically we observe between $20 \%$ and $30 \%$ UI replacement ratios.

${ }^{30}$ Costain \& Reiter (2008) argue that in the DMP model the response of the labor market tightness to changes in unemployment insurance (UI) policies is too large. The effects of $\tilde{b}$ and $p$ on the average human capital are similar in the model, so a similar problem arises. However, Hagedorn \& Manovskii (2008) argue that there are no reliable estimates of what the empirical counterpart of this response should be, given that most estimates suffer from endogeneity problems. Therefore, this paper does not address this issue. How to generate the right response to UI policies is left for future research.

${ }^{31} \mathrm{I}$ am grateful to an anonymous referee for helpful suggestions on how to disentangle these effects.
} 
equivalent of (32) in the DMP model..$^{32}$ In the DMP model the free entry condition is given by

$$
\frac{k}{q(\theta)}=\frac{1}{r+\mu+s} \cdot \frac{(1-\beta)(r+\mu+s)(p-\tilde{b})}{r+\mu+s+\beta f(\theta)}
$$

Denoting firms' profits flow by $\hat{\Phi}(\theta, p) \equiv(1-\beta)(r+\mu+s)(p-b) /(r+\mu+s+\beta f(\theta))$, clearly $\hat{\Phi}(\theta, p)$ equals profits $\Phi(\theta, \bar{\gamma}, p)$ in (28) when $\delta$ equals 0 , so (39) is the counterpart of the job creation condition (27). ${ }^{33}$ Differentiating (39) gives the counterpart of the elasticity (34) in the model with skills decay

$$
\varepsilon^{D M P}=p \cdot\left(\frac{\hat{\Phi}_{p}(\theta, p)}{\hat{\Phi}(\theta, p)}\right) \cdot\left(\eta-\frac{\hat{\Phi}_{f}(\theta, p)(1-\eta) f(\theta)}{\hat{\Phi}(\theta, p)}\right)^{-1},
$$

where as before $\hat{\Phi}_{x}(\theta, p)=\partial \hat{\Phi}(\theta, p) / \partial x$ denotes the partial derivative of profit flows with respect to variable $x \in\{p, f(\theta)\}$.

In the baseline DMP model, the elasticity of profits with respect to the job finding rate $\hat{\Phi}_{f}(1-\eta) f(\theta) / \hat{\Phi}$ is negative. ${ }^{34}$ The elasticity is negative because when the job finding rate increases workers find jobs more quickly, so the value of unemployment increases. As a result, workers ask for higher wages, which reduces profits. This dampens fluctuations in labor market tightness, precisely through the channel described by Shimer (2005). However, with unemployment history the counterpart of this term also includes the effect of the job finding rate on the endogenous human capital. This effect on human capital is strong enough to change the sign of the elasticity of profits, so $\Phi_{f}(1-\eta) f(\theta) / \Phi$ becomes positive. It increases the last term $\left(\eta-\hat{\Phi}_{f}(1-\eta) f(\theta) / \hat{\Phi}\right)^{-1}$ in (40) from 1.08 in the DMP model to 3.53 in the model with unemployment history. The difference between these two values provides an intuitive measure of the skill effect, i.e. the effect of fluctuations in the average human capital (caused by movements in the job finding rate) on the elasticity of labor market tightness.

There are two other effects, as (34) shows. There is the usual direct effect through changes

\footnotetext{
${ }^{32}$ In the DMP model the elasticity given by (34) equals 1 since aggregate and labor productivity are the same.

${ }^{33}$ To derive (39), I use that the free entry condition is $k / q(\theta)=(p-w) /(r+\mu+s)$ in the DMP model and that wages are given by

$$
w=\frac{(1-\beta)(r+\mu+s) b+\beta(r+\mu+s+f(\theta)) p}{r+\mu+s+\beta f(\theta)} .
$$

${ }^{34}$ The partial effect $\hat{\Phi}_{f}$ is given by $\hat{\Phi}_{f}=-\beta(1-\beta)(r+\mu+s)(p-\tilde{b}) /(r+\mu+s+\beta f(\theta))^{2}<0$.
} 
in productivity, which is captured by $\left(\hat{\Phi}_{p} / \hat{\Phi}\right) \cdot p$. Quantitatively this effect is similar in both models. The elasticity is 3.70 in the baseline model and 3.31 in the model with unemployment history. The final effect is due to selection effects from changes in the threshold $\bar{\gamma}$. In booms $\bar{\gamma}$ increases, which lowers the average human capital in the economy. However, quantitatively this effect is small compared to the other effects. The selection effect is captured by $\left(\Phi_{\bar{\gamma}} / \Phi\right) \cdot d \bar{\gamma} / d p$ and is equal to $-1.076 .{ }^{35}$ Overall, this quantitive exercise suggests that the effect of the job finding rate on the average human capital and firms' expected profits from hiring is the main channel that increases labor market volatility.

\section{Conclusion}

The DMP search and matching framework has become the workhorse model for the study of labor markets. Motivated by the findings in Shimer (2005), this paper studies labor market fluctuations in a search and matching model in which workers lose some skills during unemployment. Firms' hiring profits are more volatile in this model. First, because changes in aggregate productivity affect the average human capital of the pool of unemployed workers. Their human capital worsens in recessions and improves in booms. Second, workers' human capital decreases with unemployment history, and as a result so do their wages. This leads to more rigid wages for workers with longer unemployment history because their wages are closer to the value of non-market time. The paper shows that these two mechanisms deliver larger fluctuations in the vacancy-unemployment ratio. The improvement in the size of fluctuations is mild for low values of non-market time, but it is sizable for a mid-range of values standard in the literature. In this latter case the model can generate labor market fluctuations that are in line with those we observe in the data. Unemployment has a large impact on workers' labor market fortunes. This paper suggests that the effect of unemployment on workers human capital has important implications for firms' hiring decisions, and leads to larger fluctuations in labor markets.

\footnotetext{
${ }^{35}$ In Chassamboulli (2013) the selection effect works in the opposite direction, changes in firms' hiring threshold generate procyclical fluctuations in matching efficiency that lead to larger volatility in the labor market.
} 


\section{References}

Beauchemin, K. \& Tasci, M. (2013), 'Diagnosing labor market search models: a multiple-shock approach', Macroeconomic Dynamics FirstView, 1-25.

Bils, M., Chang, Y. \& Kim, S.-B. (2011), 'Worker heterogeneity and endogenous separations in a matching model of unemployment fluctuations', American Economic Journal: Macroeconomics 3(1), pp. 128-154.

Bils, M., Chang, Y. \& Kim, S.-B. (2012), 'Comparative advantage and unemployment', Journal of Monetary Economics 59(2), 150 - 165.

Cardullo, G. \& Guerrazzi, M. (2013), 'The Cyclical Volatility of Equilibrium Unemployment and Vacancies: Evidence from Italy', (51726).

Carrington, W. J. (1993), 'Wage losses for displaced workers: Is it really the firm that matters?', Journal of Human Resources 28(3), pp. 435-462.

Chassamboulli, A. (2013), 'Labor-market volatility in a matching model with worker heterogeneity and endogenous separations', Labour Economics 24(0), 217 - 229.

Coles, M. \& Masters, A. (2000), 'Retraining and long-term unemployment in a model of unlearning by not doing', European Economic Review 44(9), 1801 - 1822.

Costain, J. S. \& Reiter, M. (2008), 'Business cycles, unemployment insurance, and the calibration of matching models', Journal of Economic Dynamics and Control 32(4), 1120 - 1155.

Couch, K. A. \& Placzek, D. W. (2010), 'Earnings losses of displaced workers revisited', American Economic Review 100(1), 572-89.

den Haan, W. J., Haefke, C. \& Ramey, G. (2005), 'Turbulence and unemployment in a job matching model', Journal of the European Economic Association 3(6), 1360-1385.

Eyigungor, B. (2010), 'Specific capital and vintage effects on the dynamics of unemployment and vacancies', American Economic Review 100(3), 1214-1237.

Fallick, B. C. (1996), 'A review of the recent empirical literature on displaced workers', Industrial and Labor Relations Review 50(1), pp. 5-16.

Farber, H. S. (1997), 'The changing face of job loss in the united states, 1981-1995', Brookings Papers on Economic Activity: Microeconomics pp. 55-128.

Fujita, S. (2012), 'Declining labor turnover and turbulence'. mimeo, Federal Reserve Bank of Philadelphia.

Gertler, M. \& Trigari, A. (2009), 'Unemployment fluctuations with staggered nash wage bargaining', Journal of Political Economy 117(1), pp. 38-86.

Hagedorn, M. \& Manovskii, I. (2008), 'The cyclical behavior of equilibrium unemployment and vacancies revisited', American Economic Review 98(4), pp. 1692-1706. 
Hall, R. E. (2005), 'Employment fluctuations with equilibrium wage stickiness', American Economic Review 95(1), pp. 50-65.

Hall, R. E. \& Milgrom, P. R. (2008), 'The limited influence of unemployment on the wage bargain', American Economic Review 98(4), pp. 1653-1674.

Jacobson, L. S., LaLonde, R. J. \& Sullivan, D. G. (1993), 'Earnings losses of displaced workers', American Economic Review 83(4), pp. 685-709.

Kennan, J. (2010), 'Private information, wage bargaining and employment fluctuations.', Review of Economic Studies 77(2), 633 - 664.

Kletzer, L. G. (1998), 'Job displacement', Journal of Economic Perspectives 12(1), pp. 115136.

Ljungqvist, L. \& Sargent, T. J. (1998), 'The european unemployment dilemma', Journal of Political Economy 106(3), 514-550.

Ljungqvist, L. \& Sargent, T. J. (2007), 'Understanding european unemployment with matching and search-island models', Journal of Monetary Economics 54(8), 2139 - 2179.

Ljungqvist, L. \& Sargent, T. J. (2008), 'Two questions about european unemployment', Econometrica 76(1), 1-29.

Menzio, G. (2005), 'High frequency wage rigidity'. mimeo, University of Pennsylvania.

Mortensen, D. T. \& Nagypal, E. (2007), 'More on unemployment and vacancy fluctuations', Review of Economic Dynamics 10(3), 327 - 347.

Mortensen, D. T. \& Nagypal, E. (2007b), 'Labor-market volatility in matching models with endogenous separations', Scandinavian Journal of Economics 109(4), 645-665.

Mortensen, D. T. \& Pissarides, C. A. (1994), 'Job creation and job destruction in the theory of unemployment', Review of Economic Studies 61(0), 397-415.

Neal, D. (1995), 'Industry-specific human capital: Evidence from displaced workers', Journal of Labor Economics 13(4), pp. 653-677.

Ortego-Marti, V. (2012), 'Unemployment history and frictional wage dispersion'. mimeo.

Pavoni, N. (2011), 'Optimal unemployment insurance, with human capital depreciation, and duration dependence', International Economic Review .

Pavoni, N., Setty, O. \& Violante, G. L. (2012), 'Search and work in optimal welfare programs'. mimeo.

Pavoni, N. \& Violante, G. L. (2007), 'Optimal welfare-to-work programs', Review of Economic Studies 74(1), 283-318.

Petrongolo, B. \& Pissarides, C. A. (2001), 'Looking into the black box: A survey of the matching function', Journal of Economic Literature 39(2), pp. 390-431. 
Pissarides, C. A. (1992), 'Loss of skill during unemployment and the persistence of employment shocks', Quarterly Journal of Economics 107(4), pp. 1371-1391.

Pissarides, C. A. (2000), Equilibrium Unemployment Theory, MIT Press, Cambridge.

Pissarides, C. A. (2009), 'The unemployment volatility puzzle: Is wage stickiness the answer?', Econometrica 77(5), 1339-1369.

Pries, M. J. (2008), 'Worker heterogeneity and labor market volatility in matching models', Review of Economic Dynamics 11(3), $664-678$.

Rudanko, L. (2011), 'Aggregate and idiosyncratic risk in a frictional labor market', American Economic Review 101(6), 2823-43.

Ruhm, C. J. (1991), 'Are workers permanently scarred by job displacements?', American Economic Review 81(1), pp. 319-324.

Schoeni, R. \& Dardia, M. (2003), 'Estimates of earnings losses of displaced workers using california administrative data'. University of Michigan Population Studies Center Report 03543.

Shimer, R. (2005), 'The cyclical behavior of equilibrium unemployment and vacancies', American Economic Review 95(1), 24-49.

Shimer, R. \& Werning, I. (2006), 'On the optimal timing of benefits with heterogeneous workers and human capital depreciation'. mimeo, University of Chicago.

Silva, J. I. \& Toledo, M. (2009), 'Labor turnover costs and the cyclical behavior of vacancies and unemployment', Macroeconomic Dynamics 13, 76-96.

Silva, J. I. \& Toledo, M. (2013), 'The unemployment volatility puzzle: The role of matching costs revisited', Economic Inquiry 51(1), 836-843.

Stevens, A. H. (1997), 'Persistent effects of job displacement: The importance of multiple job losses', Journal of Labor Economics 15(1), pp. 165-188.

Topel, R. (1990), 'Specific capital and unemployment: Measuring the costs and consequences of job loss', Carnegie-Rochester Conference Series on Public Policy 33(0), 181 - 214.

von Wachter, T., Song, J. \& Manchester, J. (2009), 'Long-term earnings losses due to mass layoffs during the 1982 recession: An analysis using U.S. administrative data from 1974 to 2004'. mimeo, Columbia University. 


\section{Technical Appendix}

\section{Proof of Proposition 1}

Define the match surplus as $S(\gamma, p) \equiv J(\gamma, p)+W(\gamma, p)-U(\gamma)$. Nash Bargaining implies that

$$
\begin{aligned}
& W(\gamma, p)-U(\gamma)=\beta S(\gamma, p) \\
& J(\gamma, p)=(1-\beta) S(\gamma, p)
\end{aligned}
$$

Using (2) and (3) gives

$$
\begin{aligned}
& (r+\mu+s)(W(\gamma, p)-U(\gamma))=w(\gamma, p)-(r+\mu) U(\gamma) \\
& (r+\mu+s) J(\gamma, p)=h(\gamma) p-w(\gamma, p)
\end{aligned}
$$

Combining the above equations with Nash Bargaining and solving for wages gives

$$
S(\gamma)=\frac{h(\gamma) p-(r+\mu) U}{r+\mu+s}
$$

Given that an unemployed worker can always decide to just keep the value of non-market time $b$, clearly $(r+\mu) U(\gamma) \geq b$. Therefore

$$
S(\gamma) \leq \frac{h(\gamma) p-b}{r+\mu+s}
$$

As $\gamma$ tends to infinity, productivity $h(\gamma) p$ tends to zero, so there exists a $\bar{\gamma}$ such that $S(\bar{\gamma}, p)=0$. As a result, $J(\bar{\gamma}, p)=0$ and $W(\bar{\gamma}, p)=U(\bar{\gamma})$. In particular, using (1) and (3) it follows that

$$
\begin{aligned}
& h(\bar{\gamma}) p=w(\bar{\gamma}, p) \\
& (r+\mu) U(\bar{\gamma})=b
\end{aligned}
$$




\section{Derivation of the expected value of a filled job $\Phi(\theta, \bar{\gamma}, p)$}

This part gives further details on how to derive the expression for $\Phi(\theta, \bar{\gamma}, p)$ in $(29)$. Integrating the different terms in the above expression yields the following expression for $\Phi(\theta, \bar{\gamma}, p)$

$$
\Phi(\theta, \bar{\gamma}, p)=\left\{\phi_{1} \cdot \phi_{2} \cdot \phi_{3}+\phi_{4} \cdot \phi_{5} \cdot \phi_{6}\right\} p-\left\{\phi_{7} \cdot \phi_{5} \cdot \phi_{8}+\phi_{9}\right\} b,
$$

where, using $\alpha_{3} \equiv \mu(f(\theta)+s+\mu) /(s+\mu)$ to denote the coefficient in the distribution (26), the terms $\phi_{i}$ are given by

$$
\begin{aligned}
\phi_{1} & =\frac{\alpha_{3}}{\delta+\alpha_{3}} \\
\phi_{2} & =1-e^{-\left(\delta+\alpha_{3}\right) \bar{\gamma}} \\
\phi_{3} & =(1-\beta)\left(\frac{r+\mu+s+\delta \frac{r+\mu+s}{r+\mu}}{r+\mu+s+\beta f(\theta)+\delta \frac{r+\mu+s}{r+\mu}}\right) \\
\phi_{4} & =\beta\left(\frac{r+\mu+s+f(\theta)+\delta \frac{r+\mu+s}{r+\mu}}{r+\mu+s+\beta f(\theta)+\delta \frac{r+\mu+s}{r+\mu}}\right) \\
\phi_{5} & =\frac{\alpha_{3}}{\alpha_{1}-\alpha_{3}} \\
\phi_{6} & =e^{-\left(\alpha_{3}+\delta\right) \bar{\gamma}}-e^{-\left(\alpha_{1}+\delta\right) \bar{\gamma}} \\
\phi_{7} & =\beta\left(\frac{r+\mu+s+f(\theta)}{r+\mu+s+\beta f(\theta)}\right) \\
\phi_{8} & =e^{-\alpha_{3} \bar{\gamma}}-e^{-\alpha_{1} \bar{\gamma}} \\
\phi_{9} & =(1-\beta)\left(\frac{r+\mu+s}{r+\mu+s+\beta f(\theta)}\right) \cdot\left(1-e^{-\alpha_{3} \bar{\gamma}}\right)
\end{aligned}
$$

Rearranging, after using that $e^{-\delta \bar{\gamma}} p=h(\bar{\gamma}) p=b$ implies that $\phi_{6} \cdot p=\phi_{8} \cdot b$, gives

$$
\Phi(\theta, \bar{\gamma}, p)=\left\{\phi_{1} \cdot \phi_{2} \cdot \phi_{3}\right\} p+\left\{\left(\phi_{4}-\phi_{7}\right) \cdot \phi_{5} \cdot \phi_{8}-\phi_{9}\right\} b .
$$

Replacing the values for $\phi_{i}$ in the above expression and rearranging gives (29) in the text. 


\section{Derivation of the partial effects $\Phi_{x}(\theta, \bar{\gamma}, p)$}

This section includes the derivation of the partial effects $\Phi_{f}(\theta, \bar{\gamma}, p), \Phi_{\bar{\gamma}}(\theta, \bar{\gamma}, p)$ and $\Phi_{p}(\theta, \bar{\gamma}, p)$.

Substituting these values into (32) gives the expression of the elasticity of labor market tightness $\theta$ with respect to $p$.

To calculate $\Phi_{f}(\theta, \bar{\gamma}, p)$, it is sufficient to derive the expressions for the partials of $\phi_{i}$ with respect to $f$ using the expressions in (A10). Such derivatives are given by

$$
\begin{aligned}
& \frac{\partial \phi_{1}}{\partial f}=\frac{\delta \mu}{(s+\mu)\left(\delta+\alpha_{3}\right)^{2}} \\
& \frac{\partial \phi_{2}}{\partial f}=\frac{\mu}{s+\mu} \bar{\gamma} e^{-\left(\delta+\alpha_{3}\right) \bar{\gamma}} \\
& \frac{\partial \phi_{3}}{\partial f}=-\frac{\beta(1-\beta)\left(r+\mu+s+\delta \frac{r+\mu+s}{r+\mu}\right)}{\left(r+\mu+s+\beta f(\theta)+\delta \frac{r+\mu+s}{r+\mu}\right)^{2}} \\
& \frac{\partial \phi_{4}}{\partial f}=-\frac{\partial \phi_{3}}{\partial f} \\
& \frac{\partial \phi_{5}}{\partial f}=\frac{\alpha_{1} \frac{\mu}{s+\mu}-\alpha_{3} \beta \frac{r+\mu}{r+\mu+s}}{\left(\alpha_{1}-\alpha_{3}\right)^{2}} \\
& \frac{\partial \phi_{6}}{\partial f}=-\frac{\mu}{s+\mu} \bar{\gamma} e^{-\left(\delta+\alpha_{3}\right) \bar{\gamma}}+\beta \frac{r+\mu}{r+\mu+s} \bar{\gamma} e^{-\left(\delta+\alpha_{1}\right) \bar{\gamma}} \\
& \frac{\partial \phi_{7}}{\partial f}=\frac{\beta(1-\beta)(r+\mu+s)}{(r+\mu+s+\beta f(\theta))^{2}} \\
& \frac{\partial \phi_{8}}{\partial f}=e^{\delta \bar{\gamma}} \cdot \frac{\partial \phi_{6}}{\partial f} \\
& \frac{\partial \phi_{9}}{\partial f}=-\frac{\beta(1-\beta)(r+\mu+s)}{(r+\mu+s+\beta f(\theta))^{2}}\left(1-e^{-\alpha_{3}} \bar{\gamma}\right)+\frac{(1-\beta)(r+\mu+s)}{r+\mu+s+\beta f(\theta)} \cdot \frac{\mu}{s+\mu} \cdot \bar{\gamma} e^{-\alpha_{3} \bar{\gamma}}
\end{aligned}
$$


To calculate $\Phi_{\bar{\gamma}}(\theta, \bar{\gamma}, p)$ we need only calculate the following

$$
\begin{aligned}
& \frac{\partial \phi_{2}}{\partial \bar{\gamma}}=\left(\delta+\alpha_{3}\right) e^{-\left(\delta+\alpha_{3}\right) \bar{\gamma}} \\
& \frac{\partial \phi_{6}}{\partial \bar{\gamma}}=-\left(\alpha_{3}+\delta\right) e^{-\left(\alpha_{3}+\delta\right) \bar{\gamma}}+\left(\alpha_{1}+\delta\right) e^{-\left(\alpha_{1}+\delta\right) \bar{\gamma}} \\
& \frac{\partial \phi_{8}}{\partial \bar{\gamma}}=-\alpha_{3} e^{-\alpha_{3} \bar{\gamma}}+\alpha_{1} e^{-\alpha_{1} \bar{\gamma}} \\
& \frac{\partial \phi_{9}}{\partial \bar{\gamma}}=(1-\beta) \cdot \frac{r+\mu+s}{r+\mu+s+\beta f(\theta)} \cdot \alpha_{3} e^{-\alpha_{3} \bar{\gamma}}
\end{aligned}
$$

Finally, $\Phi_{p}(\theta, \bar{\gamma}, p)$ follows immediately from (A10)

$$
\Phi_{p}(\theta, \bar{\gamma}, p)=\phi_{1} \cdot \phi_{2} \cdot \phi_{3}+\phi_{4} \cdot \phi_{5} \cdot \phi_{6} .
$$

\section{Response of labor productivity}

Average labor productivity is given by (33). Differentiating with respect to $p$ gives

$$
d \bar{y} / d p=\partial \bar{y} / \partial p+(\partial \bar{y} / \partial f(\theta))(1-\eta) f(\theta) \varepsilon_{\theta, p}+(\partial \bar{\gamma} / \partial \bar{\gamma}) d \bar{\gamma} / d p
$$

The partial derivatives are given by

$$
\begin{aligned}
& \frac{\partial \bar{y}}{\partial p}=\frac{\alpha_{3}}{\alpha_{3}+\delta} \cdot\left(1-e^{-\left(\alpha_{3}+\delta\right) \bar{\gamma}}\right) \\
& \frac{\partial \bar{y}}{\partial f}=\left(\frac{\delta \mu^{2}}{(s+\mu)^{2}\left(\delta+\alpha_{3}\right)^{2}} \cdot\left(1-e^{-\left(\alpha_{3}+\delta\right) \bar{\gamma}}\right)+\frac{\alpha_{3}}{\alpha_{3}+\delta} \cdot \frac{\mu}{s+\mu} \cdot \bar{\gamma} e^{-\left(\alpha_{3}+\delta\right) \bar{\gamma}}\right) p-\frac{\mu}{s+\mu} \cdot \bar{\gamma} e^{-\alpha_{3} \bar{\gamma}} b \\
& \frac{\partial \bar{y}}{\partial \bar{\gamma}}=\alpha_{3} e^{-\left(\alpha_{3}+\delta\right) \bar{\gamma}} p-\alpha_{3} e^{-\alpha_{3} \bar{\gamma}} b .
\end{aligned}
$$

Using that $e^{-\delta \bar{\gamma}} p=b$ shows that $\partial \bar{y} / \partial \bar{\gamma}=0$. Intuitively, holding everything else constant, a change in the cutoff call $\bar{\gamma}$ does not affect the average labor productivity. doesn't change when only $\bar{\gamma}$ changes because the marginal worker has the same productivity. All that changes is who is the marginal worker. 


\section{Simulated unemployment history distributions}

This section describes the algorithm used to simulate the response of the distribution of unemployment histories to changes in the job finding rate - the only endogenous variable that determines the distribution. I choose a monthly grid of unemployment histories $\left\{\gamma_{0}=\right.$ $\left.0,1,2, \ldots, \gamma_{\max }=480\right\}$, where $\gamma_{\max }$ corresponds to 40 years of unemployment history. ${ }^{36}$ I begin by constructing an artificial panel of 100,000 workers. Each individual $i$ in the panel is defined by a vector $\left(\gamma_{i}\right.$, status $\left._{i}\right)$ that contains the worker's unemployment history $\gamma_{i}$ and her employment status, where status $s_{i}$ equals 1 if employed and 0 if unemployed. To simulate the initial distribution of unemployment histories and employment status, I use that the cumulative distribution function of unemployment histories is given by $G^{U}(\gamma)=1-e^{-\alpha_{3} \gamma}$, where $\alpha_{3}=\mu(f+s+\mu) /(s+\mu)$, and that in steady state the unemployment rate is given by $u=(s+\mu) /(s+\mu+f)$. More specifically, the initial allocation of unemployment history and employment status are chosen as follows:

- For each worker $i$, I generate a $1 \times 2$ randomly generated vector $\left(\gamma_{i}\right.$, status $\left._{i}\right)$ from a uniform distribution.

- Unemployment history: If the random number $\gamma_{i}$ falls in the interval $\left(G^{U}(j-1), G^{U}(j)\right)$, I assign the average unemployment history for the interval $(j-1, j)$, using that for an exponential with parameter $\alpha_{3}$ the conditional expectation is

$$
E(\gamma \mid j-1 \leq \gamma \leq j)=j-1+\frac{1}{\alpha_{3}}+\frac{1}{1-e^{\alpha_{3}}}
$$

- Employment status: if the worker's second random number status ${ }_{i}$ is lower than $1-u$ the worker is employed, otherwise she is unemployed.

Given that a worker has unemployment history between $j-1$ and $j$ is $G^{U}(j-1)-G^{U}(j)$, which equals the probability that an artificial worker $i$ draws a random number in the interval $\left(G^{U}(j-1), G^{U}(j)\right)$, the above method matches the distribution of unemployment history. Similarly, the method also matches the steady state unemployment rate. ${ }^{37}$

\footnotetext{
${ }^{36}$ Using a finer grid with weeks or days to measure unemployment histories more precisely and running the simulations weekly or daily gives practically the same results.

${ }^{37}$ Indeed, the average and standard deviation of the artificial sample matches almost perfectly $1 / \alpha_{3}$, which is the distribution mean and standard deviation. The unemployment rate also matches very closely its steady
} 
Given this artificial panel, I simulate the response of the distribution of unemployment histories to a $1 \%$ change in the job finding rate - the only endogenous variable that determines the distribution. Denote the new job finding rate by $f^{n e w}$. For each worker $i$, I generate a $T \times 3$ randomly generated vector $\left(\mu_{i t}, f_{i t}, s_{i t}\right)_{\{1 \leq t \leq T\}}$, where $T$ is the total number of periods in the simulation - i.e. the length of the panel. First I look at unemployed workers. The simulation uses $f^{\text {new }}$ as the job finding rate. For each iteration $t$ and worker $i$ :

- If $\mu_{i t} \leq \mu$ the worker dies, in which case his unemployment history is reset to 0 , since the worker is replaced by a newborn.

- If the worker does not die, the worker finds a job if $f_{i t} \leq f^{n e w}$ and becomes employed, so her status changes to status $_{i}=1$.

- If the worker does not find a job, his unemployment history increases by 1 month, i.e. $\gamma_{i}=\gamma_{i}+1$

I then look at employed workers

- If $\mu_{i t} \leq \mu$ the worker dies, in which case his unemployment history is reset to 0 and the employment status changes to unemployment, as the worker is replaced by a newborn.

- If $s_{i t} \leq s$ the worker loses her job and becomes unemployment, so her status changes to status $_{i}=0$.

The above routine is repeated for each iteration $t$ until it reaches the final period $T$. At the end of the $T$ iterations, I recover the mean and standard deviation of unemployment histories, and calculate the unemployment rate. Note that given that the distribution is exponential, the mean is a sufficient statistic. I follow this algorithm to simulate 1000 panels of 100,000 workers. I then compare the mean of unemployment histories from the simulations to the predicted mean of the new distribution of unemployment histories, which is exponential with parameter $\alpha_{3}^{\text {new }}=\mu\left(f^{\text {new }}+s+\mu\right) /(s+\mu)$. Section 2.4 discusses the results. For $T=7$, i.e. when looking at the simulated distribution after 7 months, the average unemployment history is 36.22 months from the simulations. The steady state distribution predicts an average of 36.20 months, which shows that the convergence is very fast. As a comparison, the unemployment rate from the simulations is $7.48 \%$ compared to the steady state value of $7.54 \%$.

state value. 


\section{Tables}

Table 1: Calibration values

\begin{tabular}{lllc}
\hline \hline Variable & Description & Target/Source & Value \\
\hline$f(\theta)$ & Job finding rate & Shimer $(2005)$ & 0.45 \\
$s$ & Separation rate & Shimer $(2005)$ & 0.035 \\
$\mu$ & Rate labor force exit & 40 years working life & 0.0021 \\
$r$ & Interest rate & Annual interest rate 5\% & 0.0041 \\
$\eta$ & Elasticity of $q(\theta)$ & Petrongolo \& Pissarides $(2001)$ & 0.5 \\
$r$ & Interest rate & Annual interest rate 5\% & 0.0041 \\
\hline
\end{tabular}

Note.- Rates are expressed monthly. See section 3 for details. 
Table 2: Elasticity of LABOR MARKet Tightness $\varepsilon_{\theta, \bar{y}}$

\begin{tabular}{lll}
\hline \hline$\tilde{b}$ & Baseline & Model \\
\hline 0.40 & 1.83 & 1.90 \\
0.73 & 3.94 & 7.88 \\
\hline
\end{tabular}

Note.- The effective replacement ratio $\tilde{b}$ is given by the ratio of the value of non-market time and labor productivity $b / \bar{y}$. The effective replacement ratio $\tilde{b}$ is the same in the baseline model (column 2) and in the model with unemployment history (column 3 ). See text for more details. 